\title{
Construction of a weight-based seed sorting system for the third-generation hybrid rice
}

\author{
Jianxin $\mathrm{Wu}^{1 \dagger}$, Shijun Qiu${ }^{1 \dagger}$, Menglong Wang ${ }^{1}$, Chunjue $\mathrm{Xu}^{2}$, Xing Wang Deng ${ }^{2}$ and Xiaoyan Tang ${ }^{1,2^{*}}$
}

\begin{abstract}
Background: The third-generation hybrid rice technology can be constructed by transforming a recessive nuclear male sterile (NMS) mutant with a transgenic cassette containing three functional modules: the wild type male fertility gene to restore the fertility of the mutant, the pollen killer gene that specifically kills the pollen grains carrying the transgene, and the red fluorescence protein (RFP) gene to mark the transgenic seed (maintainer). The transgenic plant produces 1:1 NMS seeds and maintainer seeds that can be distinguished by the RFP signal. However, the RFP signals in the partially filled or pathogen-infected maintainer seeds are often too weak to be detected by RFP-based seed sorting machine, resulting in intermingling of the maintainer seeds with NMS seeds.

Results: Here we constructed a weight-based seed sorting system for the third-generation hybrid rice technology by silencing the genes encoding ADP-glucose pyrophosphorylase (AGP) essential for endosperm starch biosynthesis via endosperm-specific expression of artificial microRNAs (amiRNAs). In this system, the NMS seeds have normal endosperm and are heavy, but the maintainer seeds have shrunken endosperms and are light-weighted. The maintainer seeds can be easily and accurately sorted out from the NMS seeds by weight-sorting machines, so pure and fully filled NMS seeds are available.
\end{abstract}

Conclusions: The weight-based seed sorting system shows obvious advantages over the RFP-based seed sorting system in accuracy, efficiency, and cost for propagation of pure male sterile seeds. These characteristics will significantly increase the value and transgenic safety of the third-generation hybrid rice technology.

Keywords: hybrid rice, nuclear male sterility, weight-based seed sorting, amiRNA, OSAGPL2, OSAGPS2

\section{Findings}

Heterosis utilization is the most effective way to improve crop production. Currently, hybrid rice production uses the cytoplasmic male sterile (CMS) lines or photoperiod/thermo-sensitive genic male sterile (PTGMS) lines as female parent (Cheng et al. 2007). CMS lines are caused by abnormal mitochondrial (Mt) genes, and they are propagated by crossing with the maintainer line

\footnotetext{
* Correspondence: txy@frontier-ag.com

${ }^{\dagger}$ Jianxin Wu and Shijun Qiu contributed equally to this manuscript.

'Guangdong Provincial Key Laboratory of Biotechnology for Plant

Development, School of Life Sciences, South China Normal University,

510631 Guangzhou, China

${ }^{2}$ Shenzhen Institute of Molecular Crop Design, 518107 Shenzhen, China
}

carrying normal Mt gene and identical nuclear genome (Chen and Liu 2014). The CMS hybrid seeds are produced by crossing with the restorer line carrying restorer $(R f)$ genes that can specifically inhibit the function of the aberrant Mt gene (Cheng et al. 2007; Chen and Liu 2014). However, because $R f$ genes exist in only a few germplasms, the great majority of genetic resources cannot be explored for heterosis, thus restricting the breeding of superior hybrids (Cheng et al. 2007). PTGMS lines are caused by recessive nuclear genes, and their male fertility is influenced by environmental conditions such as photoperiod and temperature (Cheng et al. 2007; Fan and Zhang 2018). PTGMS lines are propagated via self-pollination under conditions restoring the male

\section{Springer Open}

(c) The Author(s). 2021 Open Access This article is licensed under a Creative Commons Attribution 4.0 International License, which permits use, sharing, adaptation, distribution and reproduction in any medium or format, as long as you give appropriate credit to the original author(s) and the source, provide a link to the Creative Commons licence, and indicate if changes were made. The images or other third party material in this article are included in the article's Creative Commons licence, unless indicated otherwise in a credit line to the material. If material is not included in the article's Creative Commons licence and your intended use is not permitted by statutory regulation or exceeds the permitted use, you will need to obtain permission directly from the copyright holder. To view a copy of this licence, visit http://creativecommons.org/licenses/by/4.0/. 
fertility. Under conditions inhibiting the male fertility, PTGMS lines outcross with paternal lines to produce hybrid seeds (Cheng et al. 2007; Fan and Zhang 2018). PTGMS lines can cross with any plants with the wild type fertility gene, thus almost all rice germplasms can be explored for superior heterosis. However, because fertility of PTGMS lines is sensitive to environmental conditions, both propagation of PTGMS seeds and production of hybrid seeds require strict environmental conditions, and both are vulnerable to unpredictable environmental changes (Cheng et al. 2007). Nuclear male sterile (NMS) lines insensitive to environmental conditions are common in flowering plants (Shi et al. 2015). However, application NMS lines for hybrid production is restricted because pure male sterile lines cannot be produced. In 2006, DuPont-Pioneer devised Seed Production Technology (SPT) in maize by transforming the NMS mutant $m s 45$ with the wild type MS45 gene linked with the maize $\alpha$-amylase gene $Z m A A 1$ under a pollen specific promoter to disrupt pollen grains carrying the transgene, and the RFP gene under a seed specific promoter to mark the transgenic seeds (Albertsen et al. 2006). Self-pollination of the transgenic plant produced $50 \%$ male sterile seeds and 50\% transgenic seeds that could be sorted out based on the red fluorescence. Since then, various systems similar to SPT have been constructed in maize and rice with different NMS genes and pollen-killer genes, but all use RFP as the seed sorting marker (Chang et al. 2016; Wu et al. 2016; An et al. 2019; Qi et al. 2020; Wang et al. 2020; Liao et al. 2021; Song et al. 2021).

RFP-based seed sorting requires machines of high precision and complicated designs for seed delivery, florescence excision, florescence detection, image acquisition, and seed sorting (Wu et al. 2016; Song et al. 2021). However, partially filled seeds or pathogen-infected seeds often have low florescence that cannot be detected by the machine, resulting in contamination of the male sterile seeds by the maintainer seeds. To circumvent the problem, cross-pollination of NMS lines by the transgenic lines was used to propagate the NMS seeds, however, this practice is labor-intensive and low yield.

Endosperm accounts for $89-91 \%$ of the total weight of rice grain, in which the majority component is starch (Lu and Luh 1991). ADP-glucose pyrophosphorylase (AGP) catalyzes the first committed step in starch synthesis in rice (Ohdan et al. 2005). AGP comprises two large subunits (AGPL) and two small subunits (AGPS), which are respectively encoded by four (AGPL1, 2, 3, 4) and two (AGPS1, 2) family members in rice (Lee et al. 2007). AGPL2 and AGPS2 are critical for starch accumulation in rice endosperm. Mutation or RNA interference of either gene causes shrunken endosperm and reduced grain weight, but the seeds are able to germinate and grow into normal plants (Lee et al. 2007; Tang et al. 2016; Wei et al. 2017). We proposed that grain weight manipulation through transgenic approach might generate a suitable marker for seed sorting for the thirdgeneration hybrid rice technology. To test this hypothesis, we attempted to construct the weight-based sorting system by inhibiting the expression of AGPL2 and AGPS2 using artificial miRNA (amiRNA) (Warthmann et al. 2013) (Additional file 1: Methods). To ensure specific reduction of the grain weight to proper levels, we designed two amiRNAs targeting two different sites of each gene (Fig. 1a, b), each amiRNA was driven by two promoters of endosperm-specific genes, $L O C_{-}$ Os01g44220 (OsAGPL2) (Fig. 1c) and LOC_Os07g11510 (Rice Allergen 16, OsRA16) (Fig. 1d), respectively, resulting in eight recombinant amiRNA expression cassettes. We also devised a pollen-killer gene by constructing the rice $\alpha$-amylase gene OsAA ( $L O C$ Cos04g33040) fusion with the amyloplastid targeting signal peptide ASP1 of $\alpha / \beta$-hydrolase (LOC_Os01g39800) under the pollenspecific promoter of OsLSP3 (late-stage pollen-specific gene 3) (Wang et al. 2020) (Fig. 1e). The eight recombinant amiRNA expression cassettes were individually linked with the pollen-killer gene and the male fertility gene OsNP1 (No Pollen 1) (Fig. 1e), and transformed into osnp1 mutant (Chang et al. 2016). Most of the transgenic plants showed 1:1 segregation of normal and abnormal pollen (Fig. 2e-f, i), implicating single transgene insertion. A few transgenic plants showed 1:3 segregation of normal and abnormal pollen (Fig. 2g-i), implicating two transgene insertions. The transgenic plants all displayed normal seed setting (Fig. 3a), but on the same plant, some of the seeds contained full endosperm while some contained shrunken endosperm (Fig. 3b). Seeds from the same $T_{0}$ transgenic plant were sorted into two groups using a weight sorter that separates grains according to their weight. The 1000-grain weights for the seeds in the two groups showed a big difference (Fig. 3c,d). All the grains in the heavy-weight collection had normal endosperm; whereas in the lightweight collection, all grains had shrunken endosperm, and a few grains appeared to be molded (Fig. 3e). The light-weight grains showed severe reduction in AGPL2 or AGPS2 transcripts compared with the wild type grains and the heavy-weight grains from the same plants (Fig. 3f-h). These results indicated that all the constructs were capable of silencing the targeted genes, reducing the grain weight to various degrees.

The heavy-weight grains (875 in total) from $\mathrm{T}_{0}$ plants were planted, and all showed male sterility (Fig. 4a,b). Plants from the light-weight grains showed 1:1 segregation of normal and abnormal pollen grains (Fig. 4a,c), and their grains also presented separation of full and partially filled grains despite similar out-appearance 


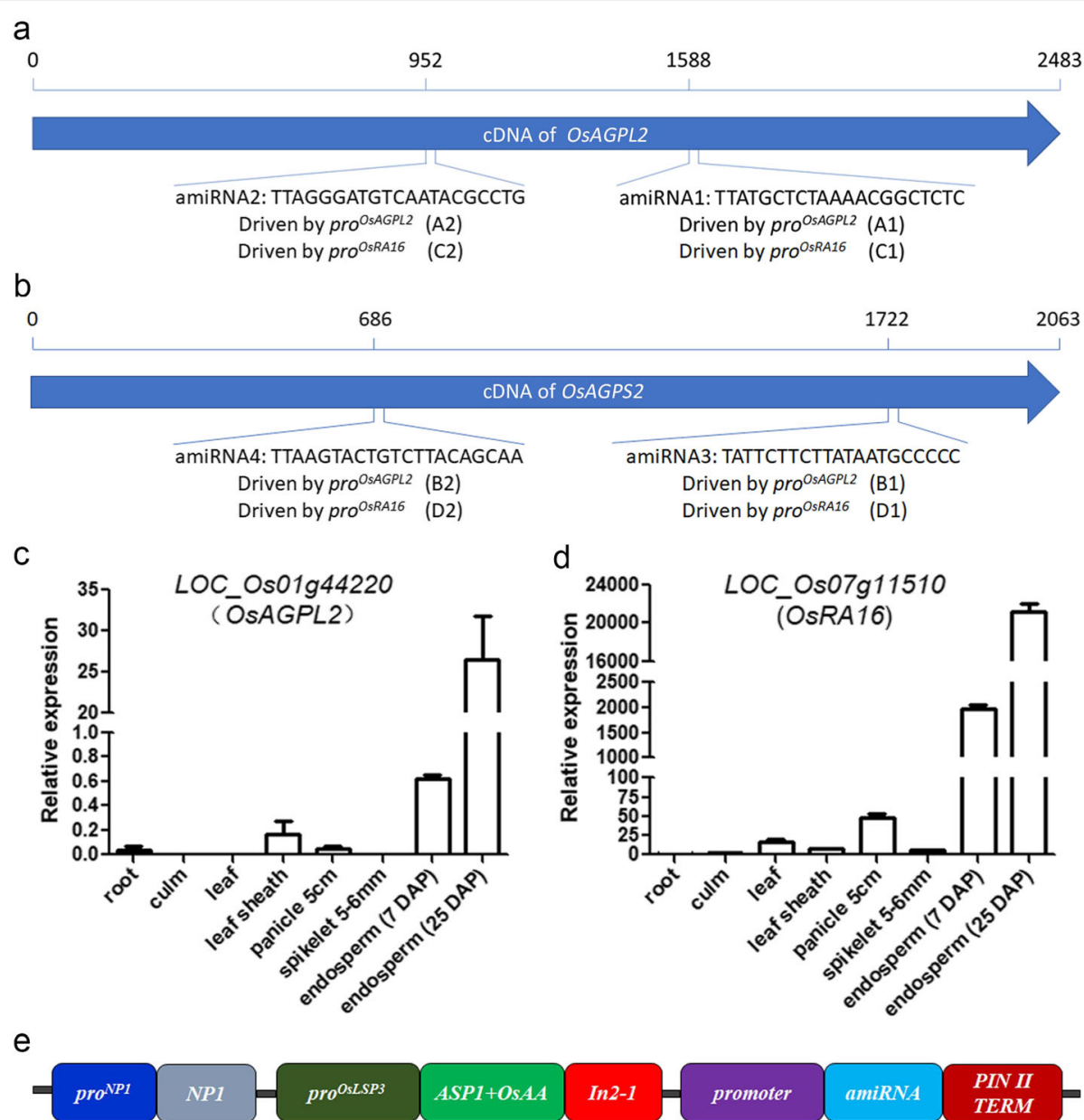

Fig. 1 Design of the weight-based seed sorting system. $(\mathbf{a}, \mathbf{b})$ Target sites and the corresponding amiRNA sequences for silencing OSAGPL2 (a) and OSAGPS2 (b). Each amiRNA gene was driven by OSAGPL2 promoter (pro ${ }^{\text {OSAGPL2 }}$ ) and OsRA16 promoter $\left(\right.$ pro $^{\text {OSRA16) }}$ ). The eight constructs were named as A1, A2, B1, B2, C1, C2, D1, and D2. (c, d) The spatial expression patterns of OsAGPL2 (c) and OsRA16 (d). The gene expression levels were determined by qRT-PCR with Actin gene as internal control. Data are shown as means $\pm S D(n=3)$. DAP, day after pollination. (e) Diagram showing the three function modules. Pro ${ }^{\mathrm{OSNP1}}$-OSNP1 is for fertility restoration, pro ${ }^{\mathrm{OL} L S P 3}$-ASP1 + OSAA-In2-1 is for pollen inactivation, and promoteramiRNA-PINII TERM is for silencing OSAGPL2 or OSAGPS2 gene. In2-1 and PINII TERM are transcriptional terminators of the maize In2-1 gene and the potato PINII (Proteinase Inhibitor II) gene, respectively (Chang et al. 2016)

(Fig. 4d-f). After weight-based sorting, the ratios of heavy- and light-weight grains were analyzed. The wildtype plant had $\sim 8 \%$ light-weight grains that were probably caused by environmental stresses, diseases and insects (Fig. 4g). Transgenic $\mathrm{T}_{1}$ plants derived from the light-weight seeds yielded $40-50 \%$ full grains (Fig. $4 \mathrm{~g}$ ). Some of the transgenic $\mathrm{T}_{1}$ plants yielded a bigger ratio of light-weight grains, probably because some of the grains were not well developed. The heavy-weight $\mathrm{T}_{2}$ seeds showed normal germination and seedling growth (Fig. 4h,i). The light-weight $\mathrm{T}_{2}$ seeds exhibited a lower seed germination rate (Fig. 4h), and seedlings were weaker before the five-leaf stage (Fig. 4i), but later became normal under regular field care (Fig. 4j). Approximately 20,000 $\mathrm{T}_{2}$ heavy-weight grains were planted for observation of male fertility, and all were sterile, indicating stable function of the amiRNA transgenes and accurate seed sorting.

The moderate weight-reduction of the maintainer seeds made the weight-based sorting system feasible to separate the maintainer seeds from male sterile seeds for the third-generation hybrid rice technology. Although the maintainer plants were slightly weaker at the early stage, later growth and seed setting were not affected. Compared with the RFP-based seed sorting system, weight-based seed sorting system has the following advantages. First, the RFP system cannot sort out the maintainer seeds with weaker fluorescence signal, resulting in intermingling of the maintainer seeds with the NMS seeds. This not only leads to transgene escaping 

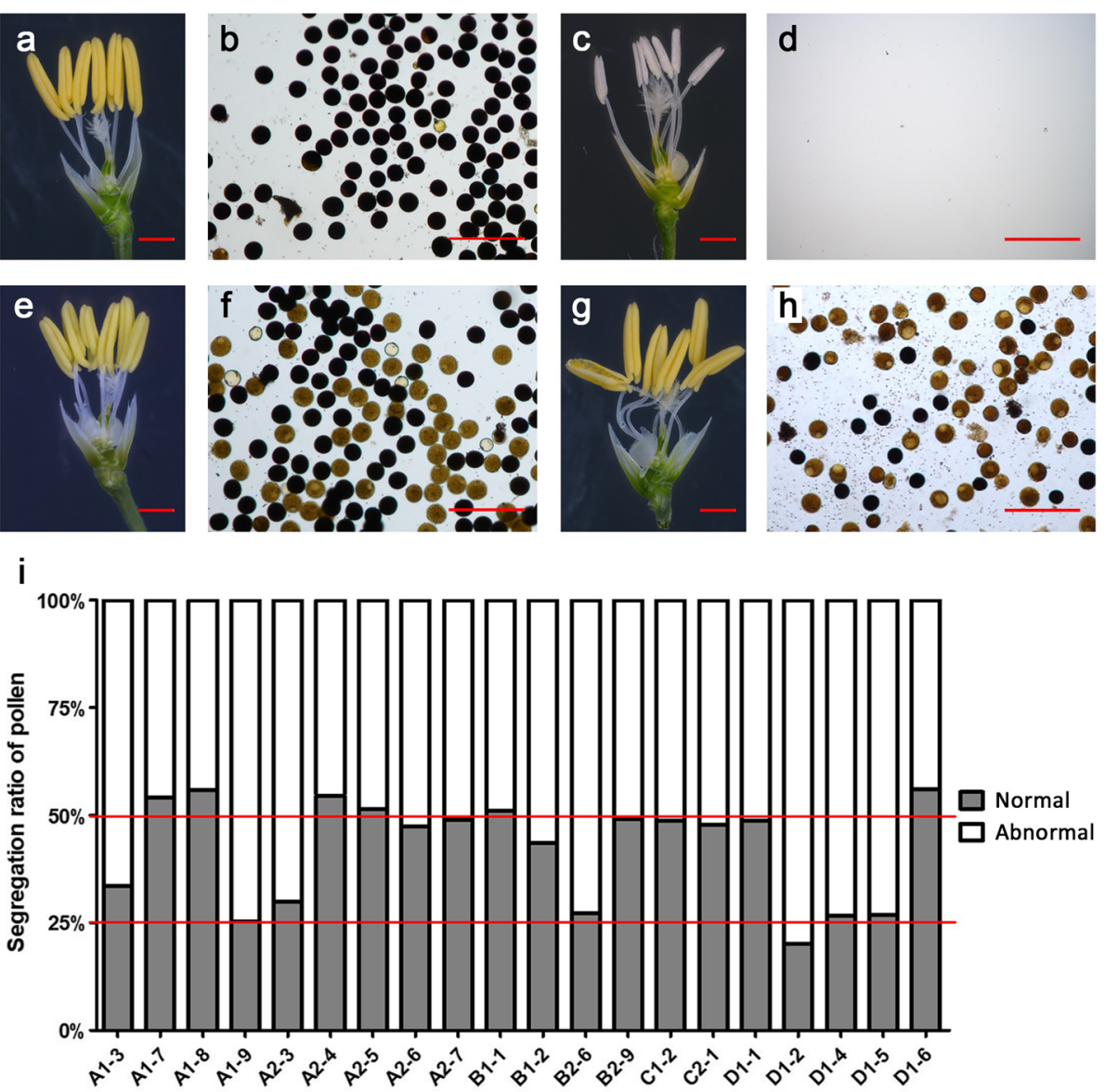

Fig. 2 Anther morphology and pollen grains of the To transgenic plants. (a-h) Anthers and pollen grains from wild type (a, b), osnp 1 mutant (c, d), and representative transgenic plants A2-6 $(\mathbf{e}, \mathbf{f})$ and B2-6 $(\mathbf{g}, \mathbf{h})$. (i) The ratios of normal pollen grains to abnormal pollen grains from different transgenic plants. Pollen grains were stained with $1 \% 12-K \mid$ solution. Bar: $(\mathbf{a}, \mathbf{c}, \mathbf{d}, \mathbf{g})=2 \mathrm{~mm} ;(\mathbf{b}, \mathbf{d}, \mathbf{f}, \mathbf{h})=200 \mu \mathrm{m}$

into environment, the presence of maintainer lines in the male sterile lines during hybrid seed production is also a problem. However, the weight-sorting machine only keeps the full seeds. The partially filled male sterile seeds are also sorted out together with the maintainer seeds, which ensures high quality of the male sterile seeds without any maintainer seeds. Even though a small fraction of the male sterile seeds are immingled with the maintainer seeds, it is not problematic to production, because the male sterile plants can only be pollinated by the maintainer line to produce the male sterile seeds. Second, the RFP-based seed sorting machines require complicate designs and are expensive for manufacturing and maintenance. Currently, the most efficient RFPbased seed sorting machine can process only $35 \mathrm{~kg}$ seeds per hour (Song et al., 2021). However, the weightbased sorting machines are common in seed industry and low cost. A regular machine can process 3000$6000 \mathrm{~kg}$ rice seeds per hour. Third, because the RFPbased seed sorting machines cannot sort out the maintainer seeds completely, production of male sterile seeds has to rely on cross-pollination of the male sterile lines by the maintainer lines, which requires separate planting of the parental plants and human-assisted pollination. These works are very laborious. However, weight-based sorting machines can sort out all the maintainer seeds efficiently, thus, direct seeding and selfpollination of maintainer lines can be used for propagation of the male sterile lines. This is suitable for mechanized production and will greatly reduce the labors and cost. Although the maintainer seeds showed a relatively lower germination rate $(\sim 70 \%)$, it is not a problem to production because most of the germinated seeds can grow into normal plants with normal seed setting under regular field care. Usually, a maintainer plant can produce $\sim 2000$ seeds; half of them are maintainer. Thus, the maintainer seeds are much more than needed for production even though they have a lower germination rate. The lower germination rate can be compensated by using more maintainers seeds during production. 
a

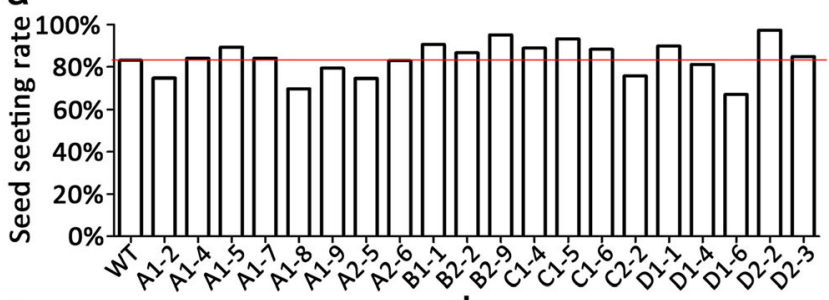

C
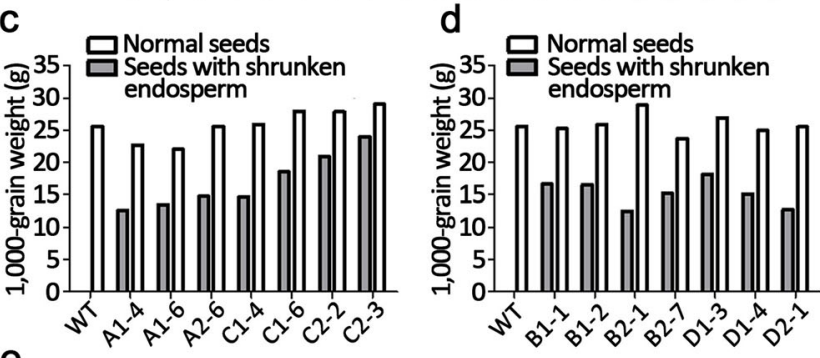

e
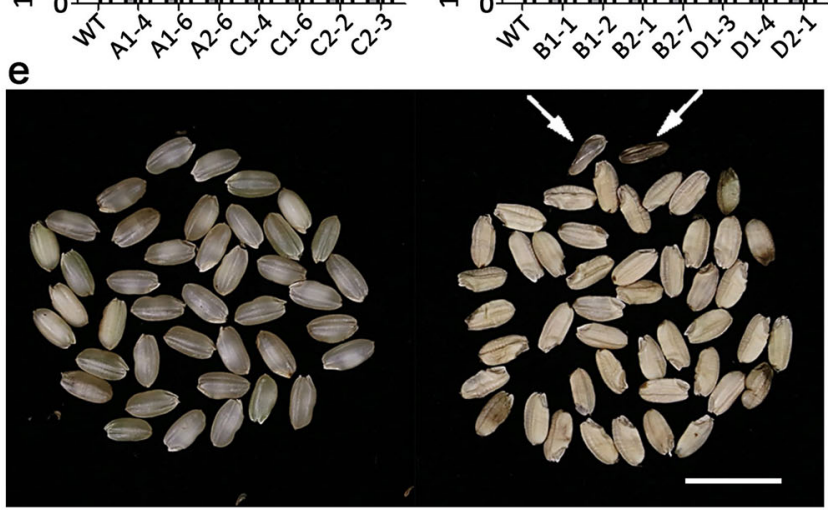

b

Full Shrunken
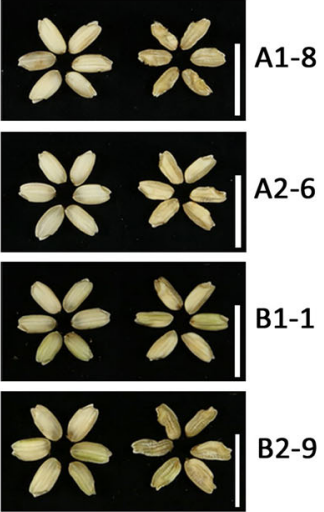

B2-9
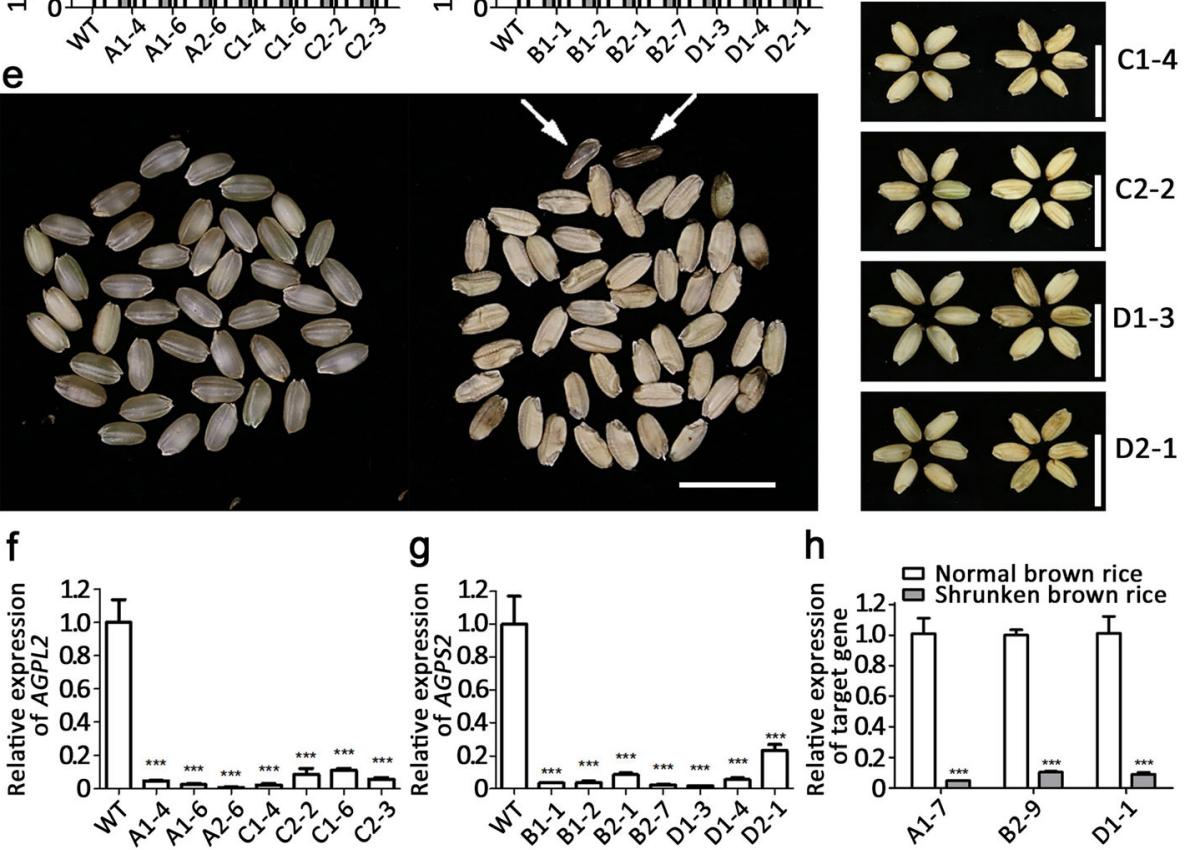

$\mathrm{g}$

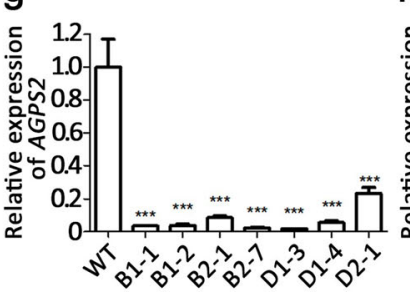

h

Fig. 3 The morphology and weight of seeds from $T_{0}$ transgenic plants. (a) The seed setting rates of the individual $T_{0}$ transgenic plants. (b) The de-hulled grains from eight $T_{0}$ transgenic plants. Grains with normal endosperm and grains with shrunken endosperm are shown. (c, d) $1000-$ grain weight of seeds from $T_{0}$ transgenic plants silencing OsAGPL2 (c) and OsAGPS2 (d.) The seeds from each individual To plant were sorted by a weight sorter into the heavy-weight and light-weight groups. The 1000-grain weight was measured for each group. (e) The de-hulled heavy and light grains from A1-4. The arrows indicate two molded grains. (f-h) The OSAGPL2 and OsAGPL2 mRNA levels in the light and heavy seeds from the corresponding gene-silencing plants. The OSAGPL2 and OSAGPS2 transcript levels in the light seeds were compared with that in the wild type seeds $(\mathbf{f}, \mathbf{g})$ or that in the heavy seed $(\mathbf{h})$. The transcript levels were determined using qRT-PCR with the ubiquitin gene as internal control. Data are shown as means \pm SD $(n=3)$. Bar: $(\mathbf{b}, \mathbf{e})=1 \mathrm{~cm}$

Besides, as various reduction of grain weight was observed in different maintainer lines, we are identifying an excellent maintainer line with a higher seed germination rate and good sorting performance.

In summary, we developed a weight-based seed sorting system for the third-generation hybrid rice technology by silencing the committed genes for starch synthesis via endosperm-specific expression of amiRNA genes. This system shows obvious advantages over the RFP-based seed sorting system in accuracy, efficiency, and cost for propagation of male sterile seeds. The application of this system will increase the transgenic safety and makes the thirdgeneration hybrid rice technology more profitable. While it is proved here in rice, the same strategy can be applied to other crops as well to expand the utilization of heterosis. In rice, manipulation of grain weight can be achieved by regulating starch synthesis. For other crops, manipulating seed weight is also possible by regulating seed size if such gene is available. 

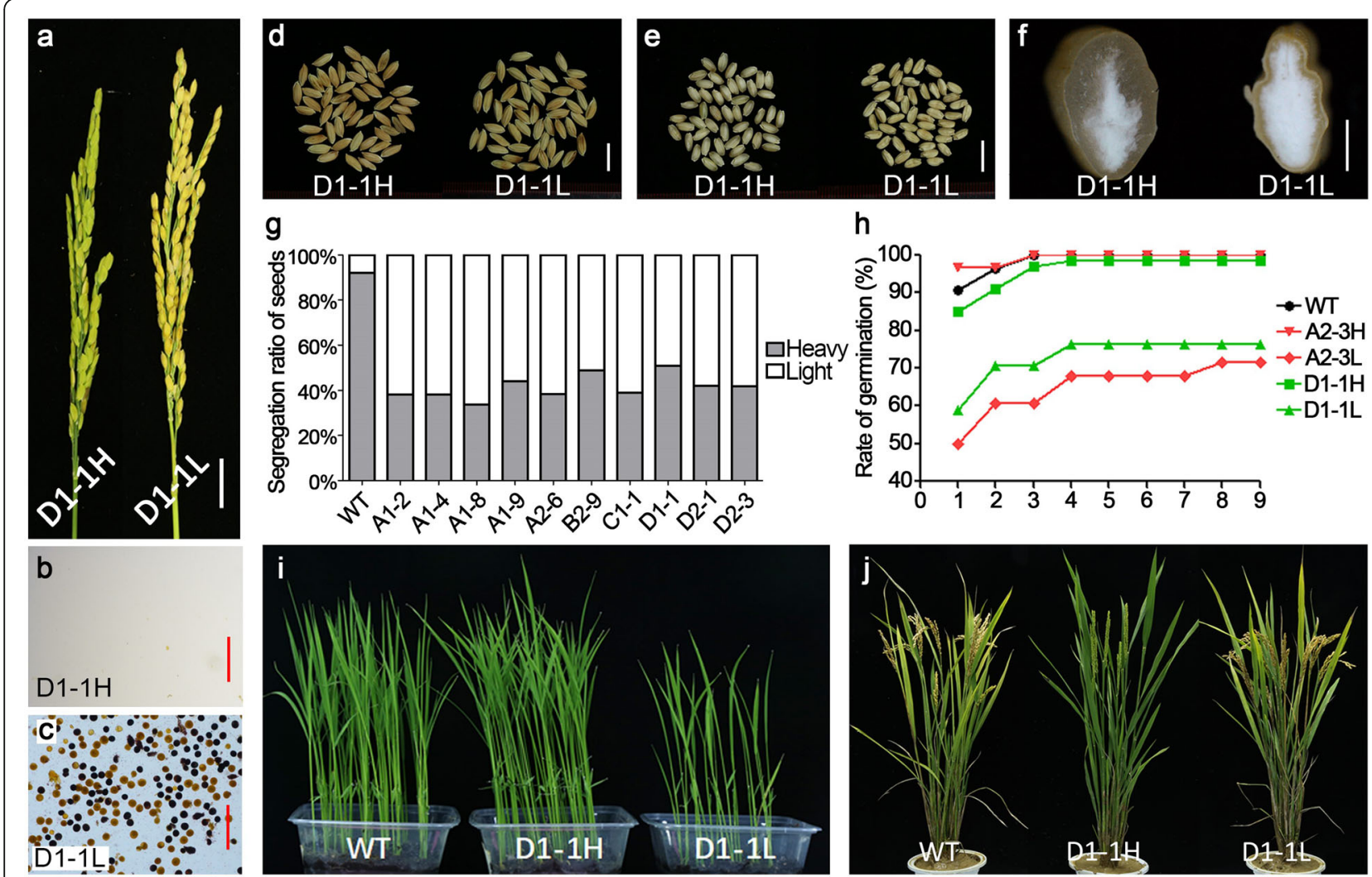

Fig. 4 Characteristics of the $T_{1}$ and $T_{2}$ generations. Panicles (a) and pollen fertility $(\mathbf{b}, \mathbf{c})$ of the $T_{1}$ plants derived from the heavy seed and light seed harvested from the D1-1 $T_{0}$ transgenic plant. The $T_{2}$ seeds harvested from the $T_{1}$ generation plants were divided into heavy-weight and light-weight groups and examined for grain out-appearance (d), de-hulled grains (e), cut endosperms (f), rates of heavy and light grains ( $\mathbf{g}$ ), seed germination (h), vigor of seedling growth (i), and appearance of mature plants (j). Pollen grains were stained with $1 \% 12-\mathrm{KI}$ solution. Results from D1-1 plant were shown as a representative. Bar: $(a)=2 \mathrm{~cm} ;(b, c)=200 \mu \mathrm{m} ;(d, e)=1 \mathrm{~cm} ; \mathrm{f}=1 \mathrm{~mm}$

\section{Abbreviations}

NMS: Nuclear male sterile; RFP: Red fluorescence protein; AGP: ADP-glucose pyrophosphorylase; AGPL: AGP large subunit; AGPS: AGP small subunit; amiRNA: Artificial microRNA; CMS: Cytoplasmic male sterile;

Mt: Mitochondrial; PTGMS: Photoperiod/thermo-sensitive genic male sterile; Rf: Restorer; SPT: Seed Production Technology; ZmAA: Maize a-amylase: OsAA: Rice a-amylase; MS45: Male sterile 45; ASP1: Amyloplastid targeting signal peptide 1; OsNP1: Rice no pollen 1

\section{Supplementary Information}

The online version contains supplementary material available at https://doi. org/10.1186/s12284-021-00510-y.

Additional file 1: Materials and Methods. Table S1. List of primers.

\section{Acknowledgements}

We thank Yanmei Yang for rice transformation, Dongfeng Liu for making the weight-based sorting machine, and Gang Xie for field care.

\section{Author contributions}

JW and XT conceived the study. SQ, MW, JW and CX performed the experiments. XT, JW and CX analyzed the data and drafted the paper. XWD reviewed and edited the paper.

\section{Funding}

The work was supported by grants from Major Program of Guangdong Basic and Applied Research (2019B030302006), National Natural Science
Foundation of China (U1901203), and Natural Science Foundation of Guangdong Province (2018B030308008 and 2021A1515010507).

Availability of data and materials

The datasets supporting the conclusions of this article are included within the article and its additional files.

\section{Declarations}

Ethics approval and consent to participate Not applicable.

\section{Consent for publication}

Not applicable.

\section{Competing interests}

The authors declare that they have no competing interests.

Received: 2 June 2021 Accepted: 7 July 2021

Published online: 13 July 2021

\section{References}

Albertsen MC, Fox TW, Hershey HP, Huffman GA, Trimnell MR, Wu Y (2006) Nucleotide sequences mediating plant male fertility and method of using same. Patent No. WO2007002267. 22 June 2006. http://europepmc.org/a rticle/PAT/WO2007002267

An X, Dong Z, Tian Y, Xie K, Wu S, Zhu T, Zhang D, Zhou Y, Niu C, Ma B, Hou Q, Bao J, Zhang S, Li Z, Wang Y, Yan T, Sun X, Zhang Y, Li J, Wan X (2019) ZmMs30 encoding a novel GDSL lipase is essential for male fertility and 
valuable for hybrid breeding in maize. Mol Plant 12(3):343-359. https://doi. org/10.1016/j.molp.2019.01.011

Chang Z, Chen Z, Wang N, Xie G, Lu J, Yan W, Zhou J, Tang X, Deng XW (2016) Construction of a male sterility system for hybrid rice breeding and seed production using a nuclear male sterility gene. Proc Natl Acad Sci U S A 113(49):14145-14150. https://doi.org/10.1073/pnas.1613792113

Chen L, Liu YG (2014) Male sterility and fertility restoration in crops. Annu Rev Plant Biol 65:579-606. https://doi.org/10.1146/annurev-arplant-050213-040119

Cheng SH, Zhuang JY, Fan YY, Du JH, Cao LY (2007) Progress in research and development on hybrid rice: a super-domesticate in China. Ann Bot 100(5): 959-966. https://doi.org/10.1093/aob/mcm121

Fan Y, Zhang Q (2018) Genetic and molecular characterization of photoperiod and thermo-sensitive male sterility in rice. Plant Reprod 31(1):3-14. https:// doi.org/10.1007/s00497-017-0310-5

Lee SK, Hwang SK, Han M, Eom JS, Kang HG, Han Y, Choi SB, Cho MH, Bhoo SH, An G, Hahn TR, Okita TW, Jeon JS (2007) Identification of the ADP-glucose pyrophosphorylase isoforms essential for starch synthesis in the leaf and seed endosperm of rice (Oryza sativa L.). Plant Mol Biol 65(4):531-546. https://doi.org/10.1007/s11103-007-9153-z

Liao C, Yan W, Chen Z, Xie G, Deng XW, Tang X (2021) Innovation and Development of the Third-Generation Hybrid Rice Technology. Crop J doi. https://doi.org/10.1016/j.cj.2021.02.003

Lu S, Luh BS (1991) Properties of the Rice Caryopsis. In: Luh BS (ed) Rice. Springer, Boston. https://doi.org/10.1007/978-1-4899-3754-4_11

Ohdan T, Francisco PB Jr, Sawada T, Hirose T, Terao T, Satoh H, Nakamura Y (2005) Expression profiling of genes involved in starch synthesis in sink and source organs of rice. J Exp Bot 56(422):3229-3244. https://doi.org/10.1093/ jxb/eri292

Qi X, Zhang C, Zhu J, Liu C, Huang C, Li X, Xie C (2020) Genome editing enables next-generation hybrid seed production technology. Mol Plant 13(9):12621269. https://doi.org/10.1016/j.molp.2020.06.003

Shi J, Cui M, Yang L, Kim YJ, Zhang D (2015) Genetic and biochemical mechanisms of pollen wall development. Trends Plant Sci 20(11):741-753. https://doi.org/10.1016/j.tplants.2015.07.010

Song S, Wang T, Li Y, Hu J, Kan R, Qiu M, Deng Y, Liu P, Zhang L, Dong H, Li C, Yu D, Li X, Yuan D, Yuan L, Li L (2021) A novel strategy for creating a new system of third-generation hybrid rice technology using a cytoplasmic sterility gene and a genic male-sterile gene. Plant Biotechnol J 19(2):251-260. https://doi.org/10.1111/pbi.13457

Tang XJ, Peng C, Zhang J, Cai Y, You XM, Kong F, Yan HG, Wang GX, Wang L, Jin J, Chen WW, Chen XG, Ma J, Wang P, Jiang L, Zhang WW, Wan JM (2016) ADP-glucose pyrophosphorylase large subunit 2 is essential for storage substance accumulation and subunit interactions in rice endosperm. Plant Sci 249:70-83. https://doi.org/10.1016/j.plantsci.2016.05.010

Wang M, Yan W, Peng X, Chen Z, Xu C, Wu J, Deng XW, Tang X (2020) Identification of late-stage pollen-specific promoters for construction of pollen-inactivation system in rice. J Integr Plant Biol 62(8):1246-1263. https:// doi.org/10.1111/jipb.12912

Warthmann N, Ossowski S, Schwab R, Weigel D (2013) Artificial microRNAs for specific gene silencing in rice. Methods Mol Biol 956:131-149. https://doi. org/10.1007/978-1-62703-194-3_11

Wei X, Jiao G, Lin H, Sheng Z, Shao G, Xie L, Tang S, Xu Q, Hu P (2017) GRAIN INCOMPLETE FILLING 2 regulates grain filling and starch synthesis during rice caryopsis development. J Integr Plant Biol 59(2):134-153. https://doi.org/1 $0.1111 /$ jipb. 12510

Wu Y, Fox TW, Trimnell MR, Wang L, Xu RJ, Cigan AM, Huffman GA, Garnaat CW, Hershey H, Albertsen MC (2016) Development of a novel recessive genetic male sterility system for hybrid seed production in maize and other crosspollinating crops. Plant Biotechnol J 14(3):1046-1054. https://doi.org/10.1111/ pbi.12477

\section{Publisher's Note}

Springer Nature remains neutral with regard to jurisdictional claims in published maps and institutional affiliations.

\section{Submit your manuscript to a SpringerOpen ${ }^{\circ}$ journal and benefit from:}

- Convenient online submission

- Rigorous peer review

- Open access: articles freely available online

- High visibility within the field

- Retaining the copyright to your article

Submit your next manuscript at $\boldsymbol{\nabla}$ springeropen.com 